\title{
Structural Performance of Advanced Composite Tow-Steered Shells with Cutouts
}

\author{
K. Chauncey Wu ${ }^{1}$, Jason D. Turpin ${ }^{2}$, Bret K. Stanford ${ }^{3}$ \\ and Robert A. Martin ${ }^{4}$ \\ NASA Langley Research Center, Hampton, Virginia 23681
}

\begin{abstract}
The structural performance of two advanced composite tow-steered shells with cutouts, manufactured using an automated fiber placement system, is assessed using both experimental and analytical methods. The shells' fiber orientation angles vary continuously around their circumference from $\pm \mathbf{1 0}$ degrees on the crown and keel, to \pm 45 degrees on the sides. The raised surface features on one shell result from application of all 24 tows during each fiber placement system pass, while the second shell uses the system's tow drop/add capability to achieve a more uniform wall thickness. These unstiffened shells were previously tested in axial compression and buckled elastically. A single cutout, scaled to represent a passenger door on a commercial aircraft, is then machined into one side of each shell. The prebuckling axial stiffnesses and bifurcation buckling loads of the shells with cutouts are also computed using linear finite element structural analyses for initial comparisons with test data. When retested, large deflections were observed around the cutouts, but the shells carried an average of 92 percent of the axial stiffness, and 86 percent of the buckling loads, of the shells without cutouts. These relatively small reductions in performance demonstrate the potential for using tow steering to mitigate the adverse effects of typical design features on the overall structural performance.
\end{abstract}

\section{Introduction}

Cutouts are prominent features on many, if not all, aerospace structures. These openings can range in size from very large (Figure 1) to very small, and are necessary to provide for loading and unloading of passengers or cargo, personnel access for maintenance and inspection, or windows and vents. However, the presence of such cutouts typically results in significant discontinuities in the structural load paths and corresponding losses in structural performance (Refs. 1 and 2). Traditionally, these losses in overall stiffness and strength are mitigated by substantial reinforcement of the remaining structure around the cutout boundary (Ref. 2). However, an alternative solution for structures built with laminated fibrous composites may be to exploit the highly directional nature of composites to maneuver the global applied loads around or away from the cutout (Refs. 3 and 4), with the goal of minimizing the additional reinforcements and associated weight penalty required around that discontinuity.

${ }^{1}$ Senior Aerospace Engineer, Structural Mechanics and Concepts Branch, Research Directorate

2 LARSS student assigned to the Structural Mechanics and Concepts Branch, Research Directorate.

AIAA Member. Sponsored by the Kansas Space Grant Consortium, Wichita, Kansas 67260

${ }^{3}$ Aerospace Engineer, Aeroelasticity Branch, Research Directorate. AIAA Member

${ }^{4}$ Aerospace Engineer, Mechanical Systems Branch, Engineering Directorate 


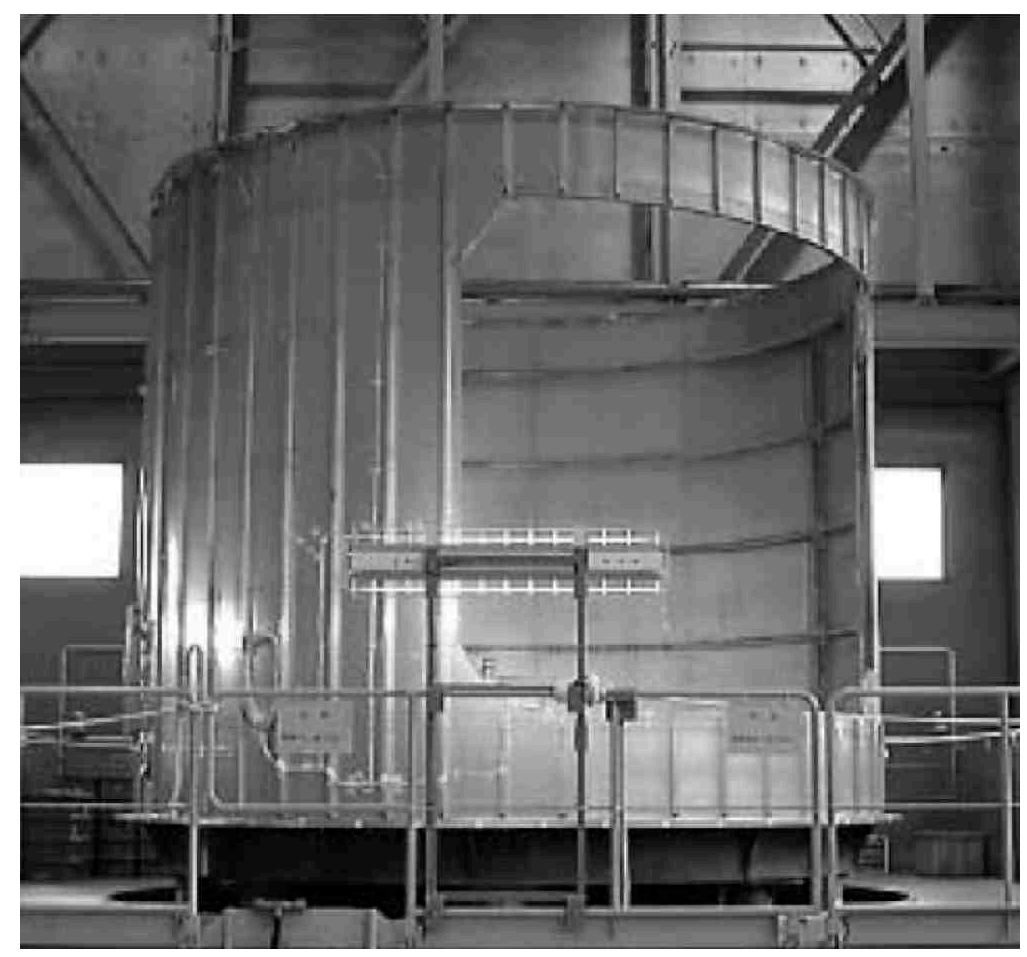

Figure 1. Aerospace structure with a large cutout (JAXA).

Strength and stiffness tailoring of conventional composite laminates has typically been achieved by deploying integer numbers of unidirectional plies that are oriented at one of a limited subset (typically $0, \pm 45$ and 90 degrees) of the wider range of possible fiber orientation angles. When this fiber orientation angle is instead allowed to vary continuously over the structural planform within each ply, these tow-steered designs are designated as advanced composite structures (Ref. 5) to better differentiate them from the conventional straight-fiber laminates. These tow-steered composites are readily fabricated using automated fiber placement systems (Figure 2, Refs. 6 and 7) that are now widely used in the aerospace industry for fabrication of primary structures. These large computer-numerically-controlled machine tools can laminate a large number of continuous, unidirectional prepreg composite tows or slit-tape material, each between $1 / 8$ to $1 / 2$ in.-wide, onto a tool surface, while also precisely and accurately following pre-defined curvilinear spatial paths.

Because advanced composite tow-steered structures have not been widely deployed in operational service, they have not been tested as extensively as more conventional straight-fiber composites. In addition, the techniques required for their structural design, modeling, analyses and certification are not currently as well defined or understood as they are for more conventional composites. To expand the database of knowledge and experience with advanced composite structures, two prototype tow-steered composite shells were designed (Ref. 8), manufactured (Ref. 9) and evaluated under end compression loads (Ref. 10).

Experimental studies and preliminary finite element analyses of these baseline shells were performed to evaluate their structural response under axial compression loads (Ref. 10). The observed prebuckling, global buckling and postbuckling behaviors for both shells described therein were characterized as elastic, with no visible indication of material damage after the tests. 
This assessment was verified by repeating the compression test for one of the shells, with minimal differences noted between these tests in the measured prebuckling axial stiffness and global buckling load. To take advantage of this result, these same composite shells were modified to include cutouts and reevaluated in this study.

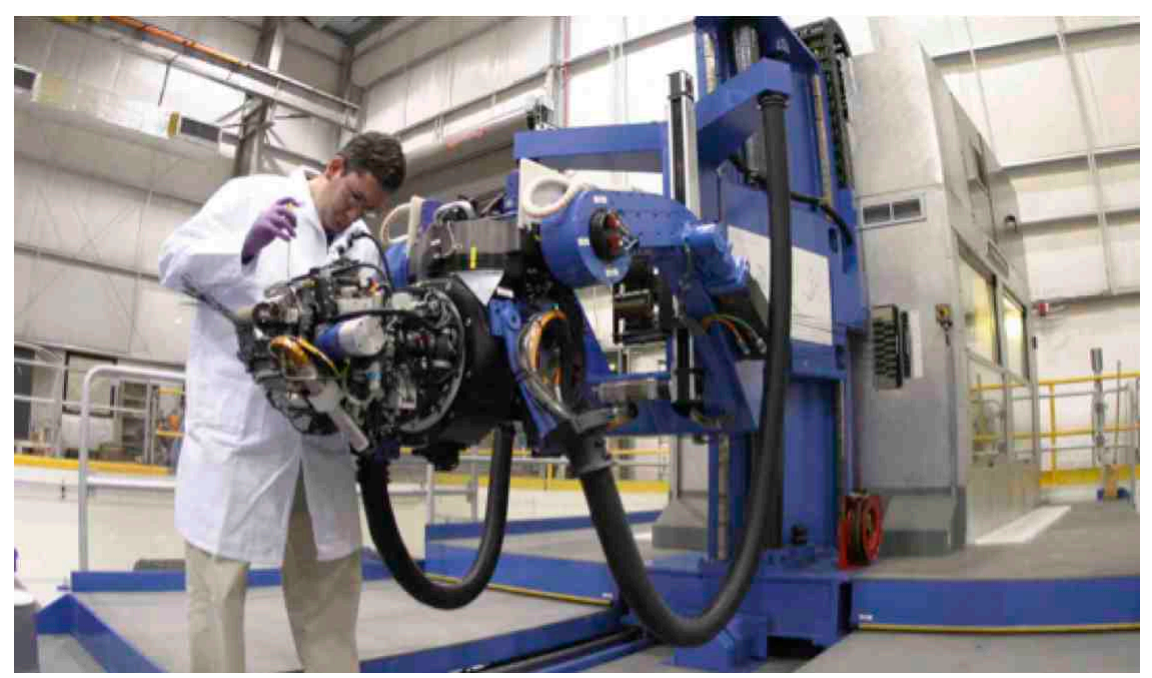

Figure 2. Fiber placement system (Lockheed Martin).

\section{Tow-steered shell description}

Both of the unstiffened shells evaluated in this study have fiber orientation angles that vary continuously around the cylinder circumference. These shells are designed to have different cross-sectional bending stiffnesses about their transverse axes, as described in Ref. 8 . The fiber orientation angle $\Theta$ is steered to vary continuously from \pm 10 degrees on the shell crown and keel, to \pm 45 degrees on the shell sides along a constant-radius circular arc, as illustrated in Figure 3. One possible application for this type of structure could be an advanced commercial aircraft fuselage, which may be assumed to behave like a beam in bending under applied flight loads. In this application, the fuselage crown and keel experience longitudinal compression and tension loads, and the shell sides are subjected to shear as the loads transfer between the crown and keel.

These cylindrical shells are fabricated using an automated fiber placement system, as described in Ref. 9. The nominal laminate thickness is approximately $0.040 \mathrm{in}$., with a nominal inner diameter for both shells of 16.266 in. and a 35.0-in. overall length. The shells are manufactured using 1/8 in.-wide IM7/8552 graphite/epoxy slit tape material oriented in a nominal 8-ply, $[ \pm 45 / \pm \Theta]_{\mathrm{S}}$ layup, where $\Theta$ is the steered fiber orientation angle described above. Measured and reference material properties used for the shell finite element analyses are provided in Ref. 10.

During fabrication, a maximum of 24 tows are placed by the fiber placement system at each location on the shell planform. When all 24 tows are placed during each pass of the fiber placement system (also called a course), a regular pattern of thicker tow overlaps (up to 16 plies, or 0.080 in. thickness) is generated between adjacent courses on the shell crown and keel regions, as shown in Refs. 8 to 10 . However, these courses are defined and spaced so that they do not overlap at all along the shell sides. These resulting laminate thickness build-ups lead to 
designation of this test specimen as the shell with overlaps (also called Shell A in Ref. 10). For the second test specimen, individual tows were cut (or "dropped") or added at various points during its fabrication, resulting in a more uniform laminate thickness (Ref. 9) and subsequent designation as the shell without overlaps (or Shell B in Ref. 10).

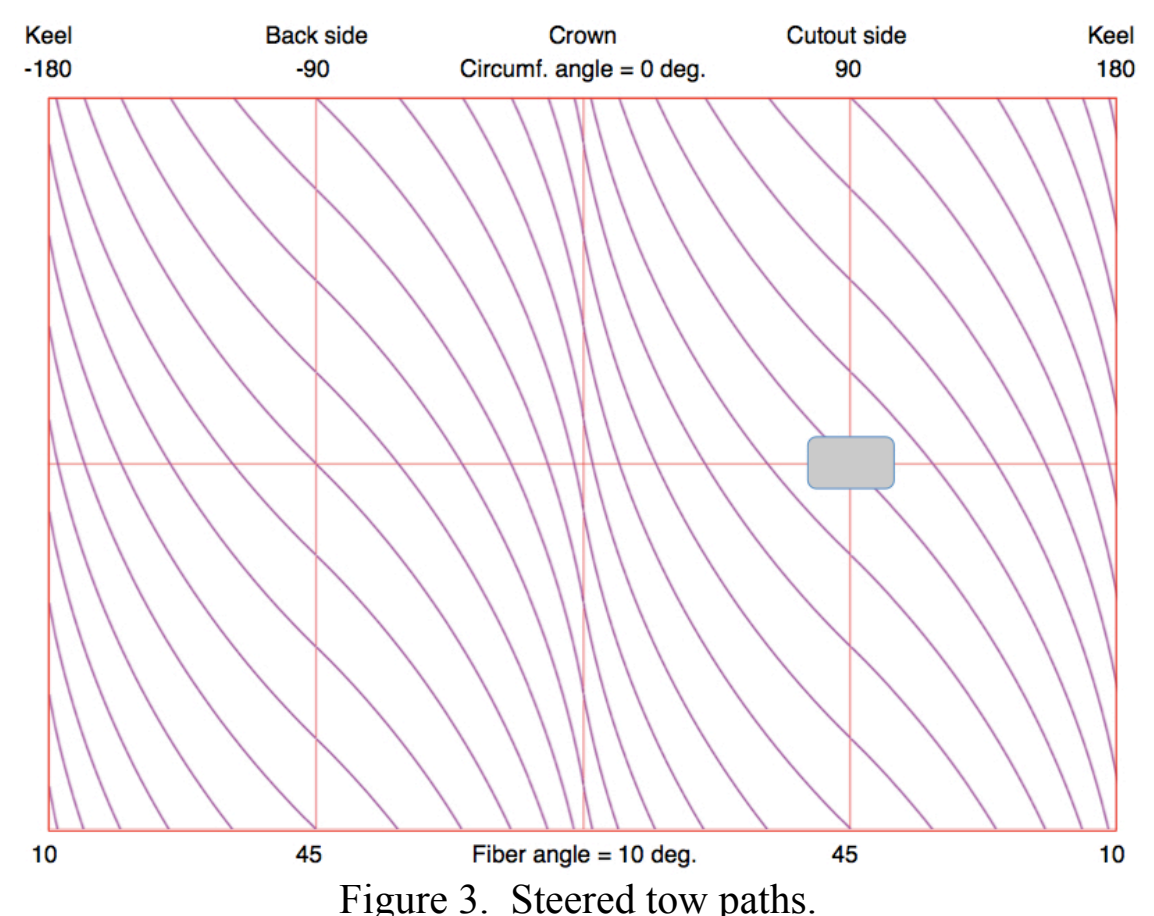

After the pristine-shell tests described in Ref. 10 were completed, flash thermography (Ref. 11) was performed to identify any potential internal damage caused by the baseline compression tests. No obvious major damage to either shell was noted during this assessment. Following this non-destructive examination, a single cutout is then machined into the center of one side of each shell (see Figure 3) where the layup is approximately $[ \pm 45]_{2 \mathrm{~s}}$. These cutouts (see Figure 4) are sized and oriented to represent a passenger access door on a commercial aircraft (Ref. 12), and measure $3 \mathrm{in}$. along the shell longitudinal dimension by $4-7 / 8 \mathrm{in}$. (approximately $1 / 3$ of the nominal shell diameter) in the circumferential dimension, with $1 / 2$-in. corner radii. The shells are then prepared for testing by installing 40 additional strain gages in back-to-back pairs of axial, biaxial and triaxial rosettes around the perimeter of the cutout, also shown in Figure 4. After the strain gages are installed, the region around the cutouts is repainted with a black base coat and speckled for measurements gathered with 3-dimensional digital image correlation (DIC) systems (Ref. 13) during testing.

\section{Shell compression test set-up}

Initial compression tests of the tow-steered shells were performed to evaluate their structural performance, and presented in Ref. 10. In these baseline tests, Shell A, the shell with overlaps, exhibited a linear prebuckling axial stiffness of $531.2 \mathrm{klb} / \mathrm{in}$., and buckled at $38.8 \mathrm{klbs}$. Shell B, the shell without overlaps, had a prebuckling stiffness of $328.7 \mathrm{klb} / \mathrm{in}$., and buckled at $17.2 \mathrm{klbs}$. Both shells responded elastically throughout the applied loading, with no visible indications of 
material damage visible after the tests concluded. The shells were loaded into deep postbuckling to approximately two times the end shortening observed at global buckling, but they were not loaded to material failure.

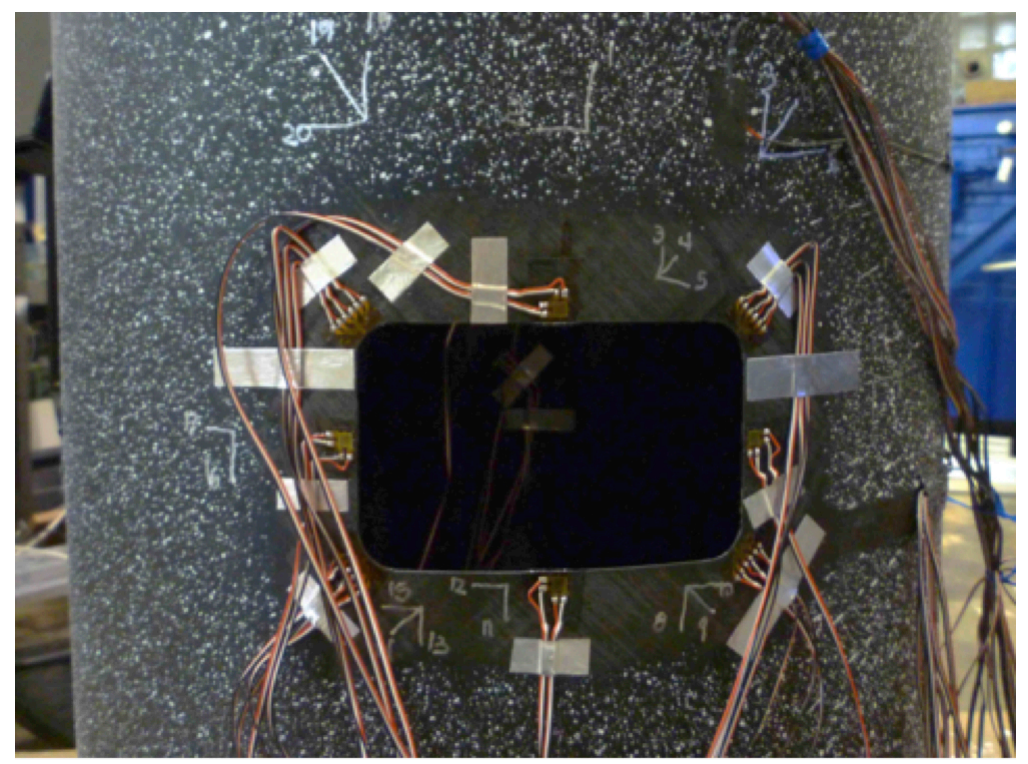

Figure 4. Detail of cutout and surrounding strain gages.

The same test setup and hardware described in Ref. 10 are deployed here for the tests of the shells with cutouts. However, the shell orientation is modified from the previous tests by rotating the shell 90 degrees about its longitudinal axis. The cutout on the shell side now faces out towards the test bay (see Figure 5), which allows better viewing of the cutout and its surroundings with a DIC system. In this new orientation, the stiffer shell crown and keel are now aligned along the transverse (left-right) axis of the test stand, and a second DIC system is mounted to assess the structural response of the shell crown on the left side of the test stand.

\section{Shell compression test results}

In this study, tests of these tow-steered composite shells with cutouts are performed to assess their structural behavior under end compression loading. Their resulting axial stiffness, buckling and postbuckling behaviors are measured, characterized, and compared with the corresponding baseline data from Ref. 10. These two sets of results are directly comparable because the same test articles and methodologies are used, with the only difference being the inclusion of the cutouts in the present test articles.

\section{A. End shortening, axial stiffness and buckling}

Displacement transducers are located at each of the four corners of the test stand to measure the relative motion of the platens while the shell is loaded. These individual measurements are averaged, and the results are plotted against the axial load in Figures 6 and 7 for Shells A and B, respectively. As discussed in Ref. 10 for the shells without cutouts, these present shells' loadend shortening response can be separated into several distinct zones. These zones are numbered 
1), linear prebuckling, 2) postbuckling (occurring in a matter of milliseconds), 3) nonlinear elastic unloading, and 4) linear elastic unloading, as noted in Figures 6 and 7.

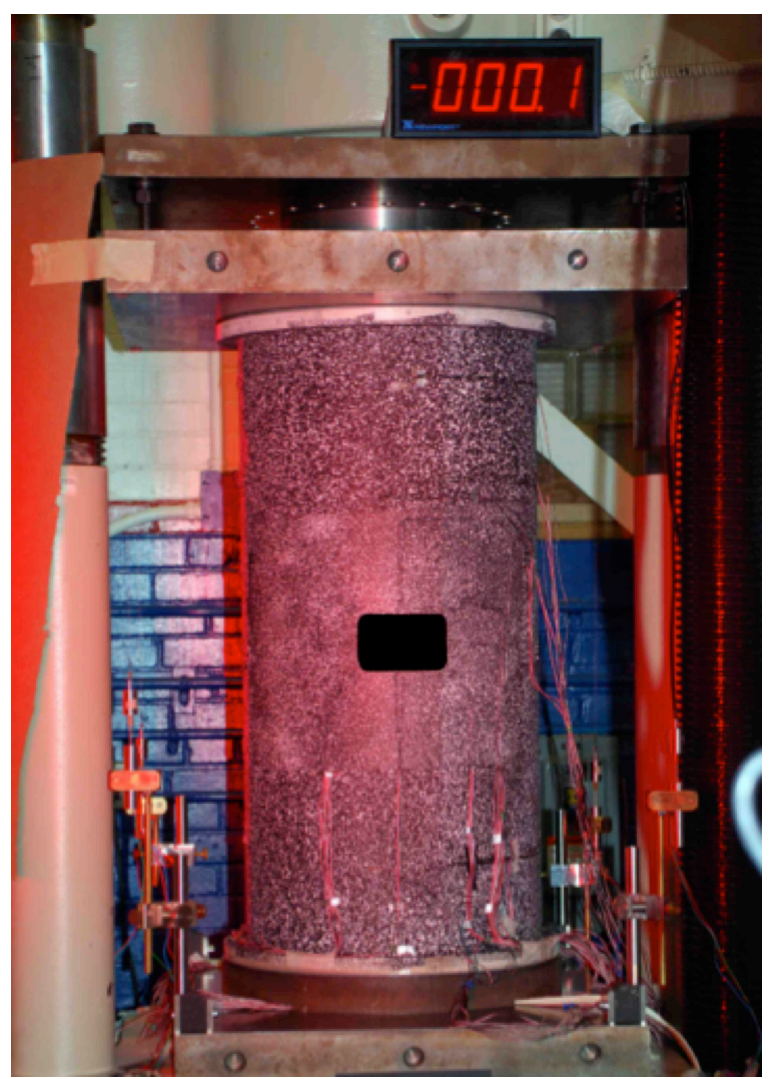

Figure 5. Tow-steered shell with cutout in test stand.

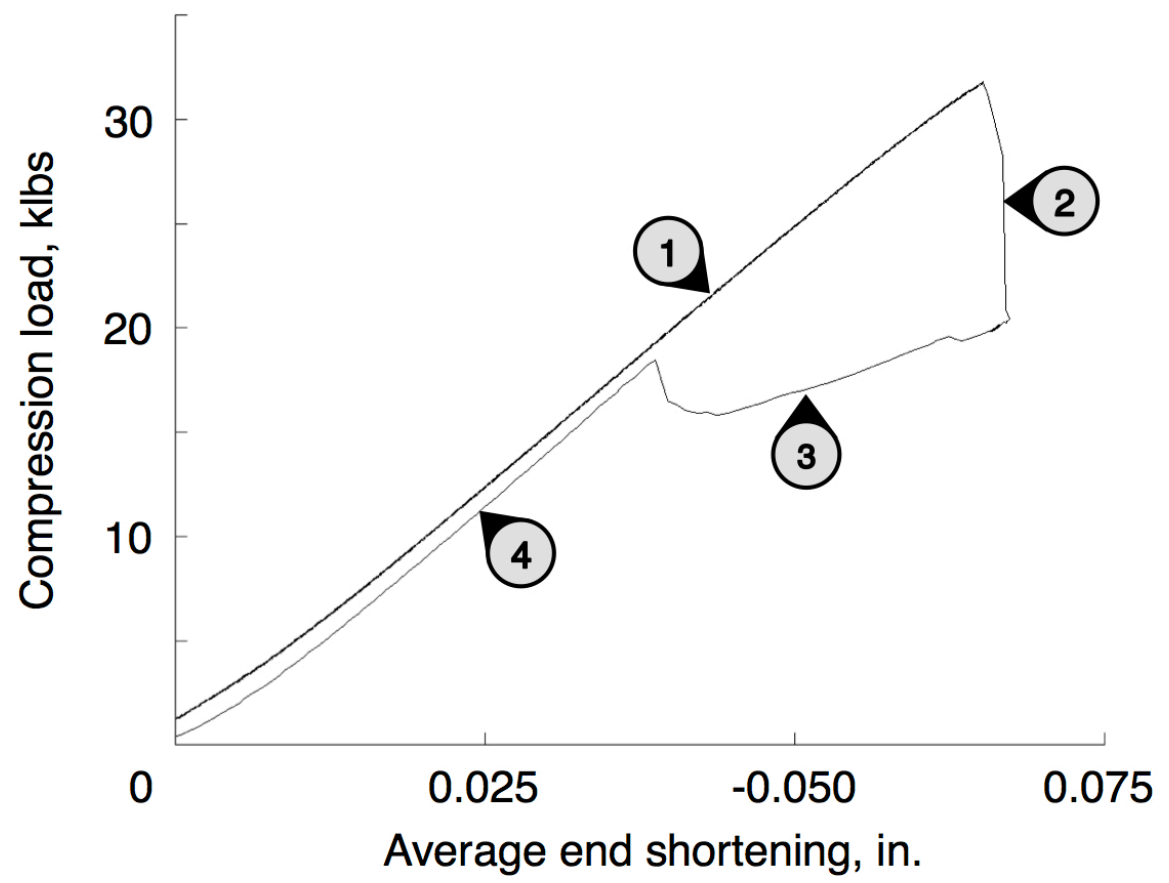

Figure 6. Shell A axial load vs. end shortening. 


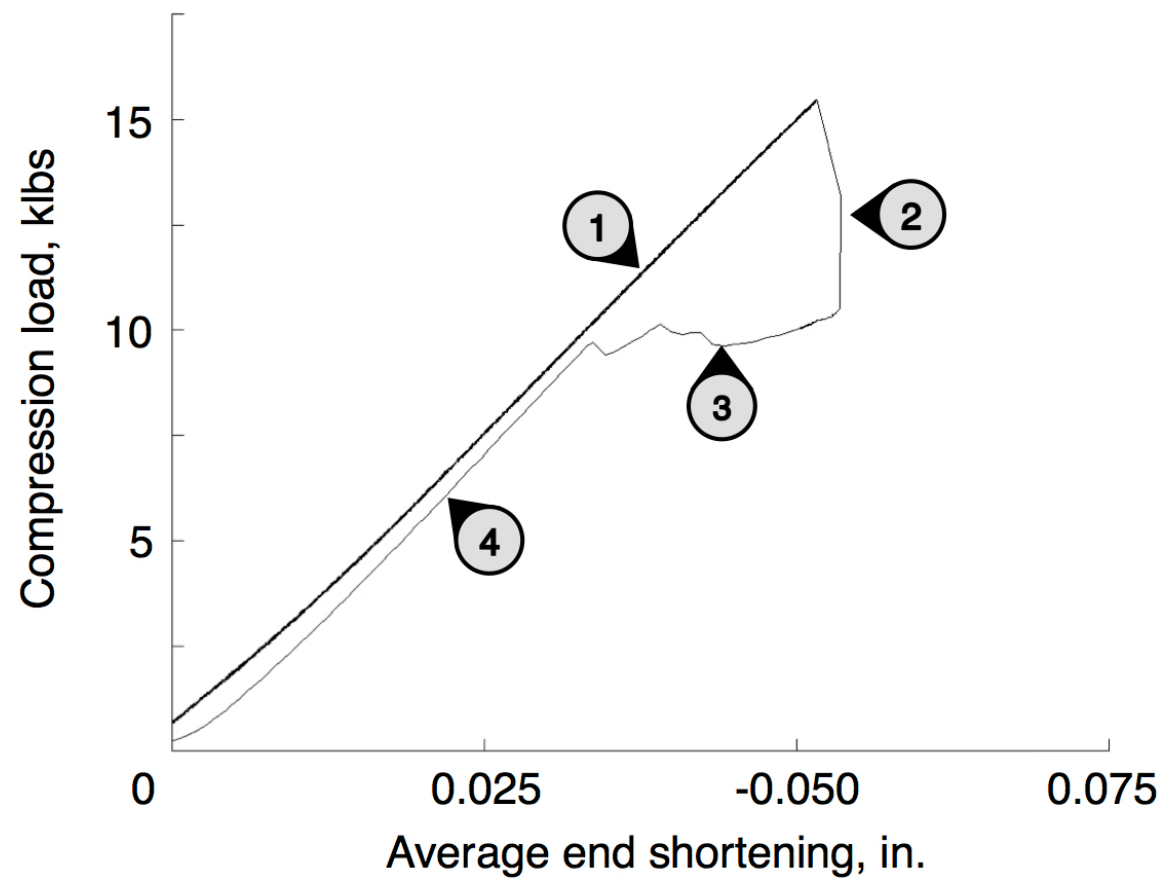

Figure 7. Shell B axial load vs. end shortening.

The prebuckling axial stiffness is calculated from a least-squares best fit slope to the linear portion of the shell load-end shortening curve in Zone 1. The measured axial stiffnesses from the present tests are $497.1 \mathrm{klb} / \mathrm{in}$. for Shell A, and $299.5 \mathrm{klb} / \mathrm{in}$. for Shell B. This measured axial stiffness of Shell A with a cutout is 66 percent higher than that of Shell B with a cutout, as compared to 62 percent in the baseline tests in Ref. 10. In addition, these axial stiffnesses for Shells A and B with cutouts are 94 and 91 percent (respectively) of the corresponding axial stiffnesses for the shells without cutouts, for an average stiffness reduction of 7 percent.

At the juncture between Zones 1 and 2, Shells A and B with cutouts fail in global buckling at 31.8 and $15.5 \mathrm{klbs}$ axial load, respectively. This buckling load for Shell A with a cutout is 105 percent higher than that of Shell B with a cutout, whereas the corresponding value was 126 percent from the baseline tests. These values are 82 and 91 percent (respectively) of the buckling load for the same shells tested without the cutout, resulting in an average reduction in buckling load of 14 percent.

Immediately upon global buckling, the axial load drops precipitously to 20.3 and 10.5 klbs for Shells A and B with cutouts, respectively, in Zone 2. Without a cutout, Shell B supports a stable postbuckling load of $12.6 \mathrm{klbs}$, which is 20 percent greater than the postbuckling load for that shell with a cutout. However, the pristine Shell A without the cutout carries a stable postbuckling load of $17.3 \mathrm{klbs}$, which is 15 percent lower than the stable postbuckling load for the same shell with a cutout. Because intuition might suggest that the stable postbuckling load should be lower in the presence of a cutout, this latter result seems counterintuitive and should be investigated more thoroughly using detailed nonlinear structural analyses. The measured shell structural performance results are summarized in Table 1 below. 
Table 1. Measured performance for shells with cutouts

$\begin{array}{lrr} & \text { Shell A } & \text { Shell B } \\ \text { Prebuckling axial stiffness, klb/in. } & 497.1 & 299.5 \\ \text { Buckling load, klbs } & 31.8 & 15.5 \\ \text { Postbuckling load, klbs } & 20.3 & 10.5\end{array}$

\section{B. Prebuckling acreage strains}

Laminate surface strains are measured during the shell compression tests using a total of 110 strain gages affixed in back-to-back pairs to the shell inner and outer surfaces. These gages, mounted in axial, transverse and shear rosettes, provide data on the shell structural response at discrete locations across the shell planform. The majority of these gages are deployed across the shell acreage near the crown, keel and sides, as shown in Figure 8. Selected acreage strains are plotted here against axial load from both shell compression tests and discussed in more detail.

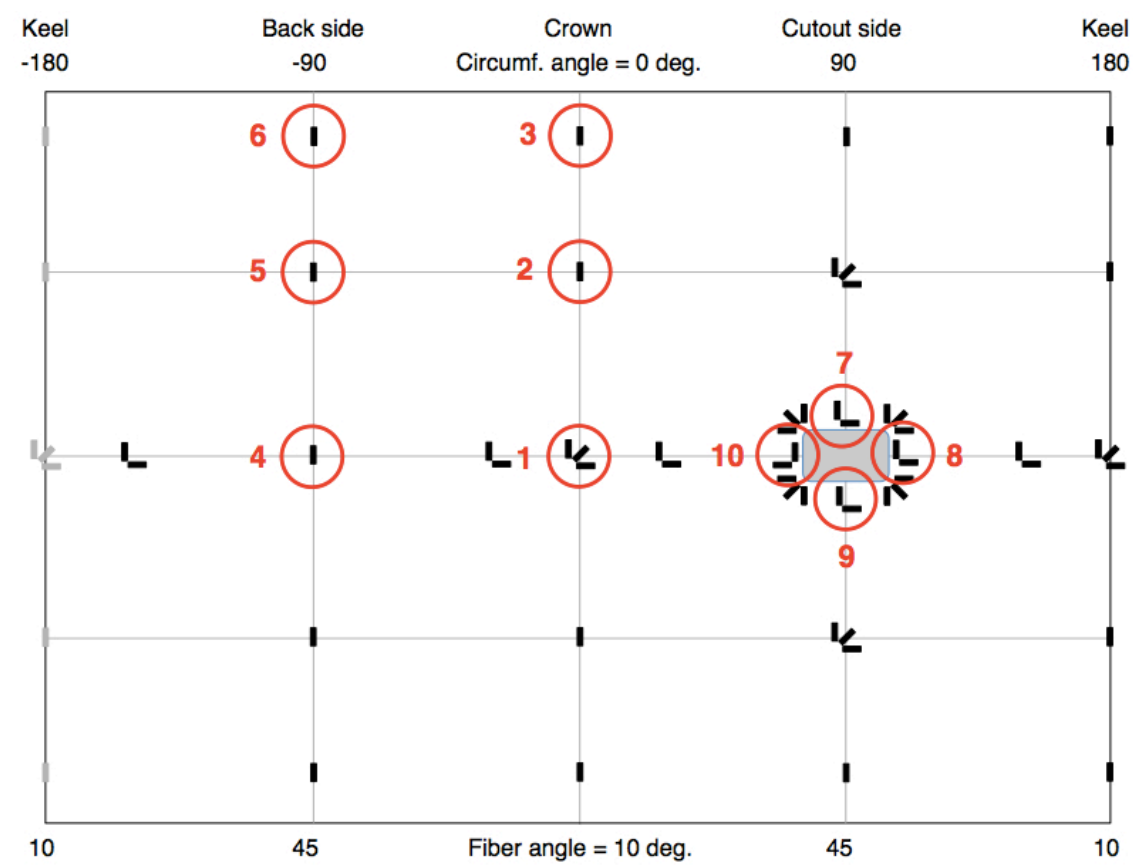

Figure 8. Shell gage rosette locations (exterior planform shown).

Axial strains from gages located along the crown of Shells A and B are plotted against the axial load up to global buckling in Figures 9 and 10, respectively. These gage pairs, located at the shell mid-length, at 75 percent of the shell length, and adjacent to the upper potted end, are designated as rosette locations (abbreviated as RL) 1, 2 and 3, respectively, in Figure 8. After some initial nonlinearities at low loads, these strains for Shell A generally increase in proportion to the load, and exhibit monotonic divergence up to buckling. In comparison, the strains at the same locations on Shell B are much more nonlinear, although they mostly exhibit similar monotonic behavior. Similar trends are also noted in the measured strains for both shells along the lower half of the crown and along the keel, and are consistent with the biaxial symmetry of the shells. 


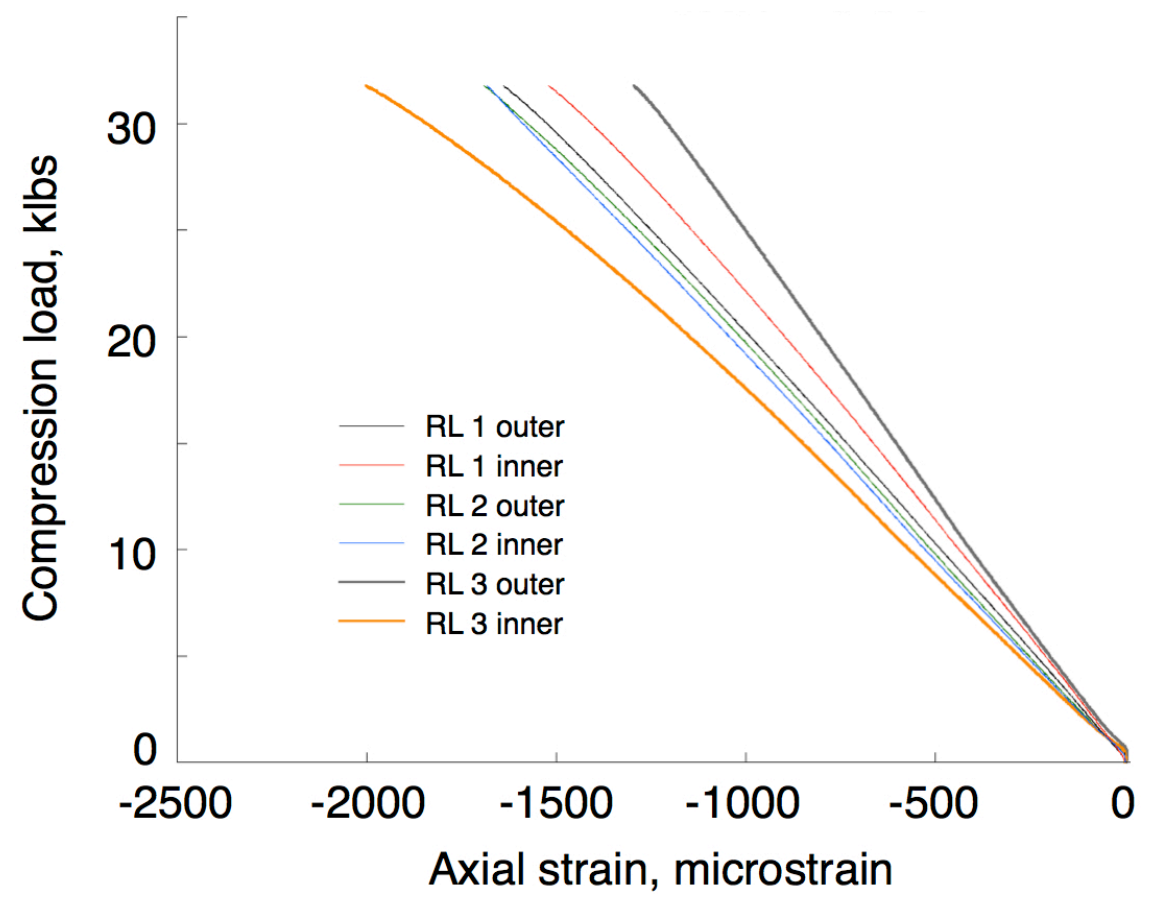

Figure 9. Shell A crown axial load vs. axial strain.

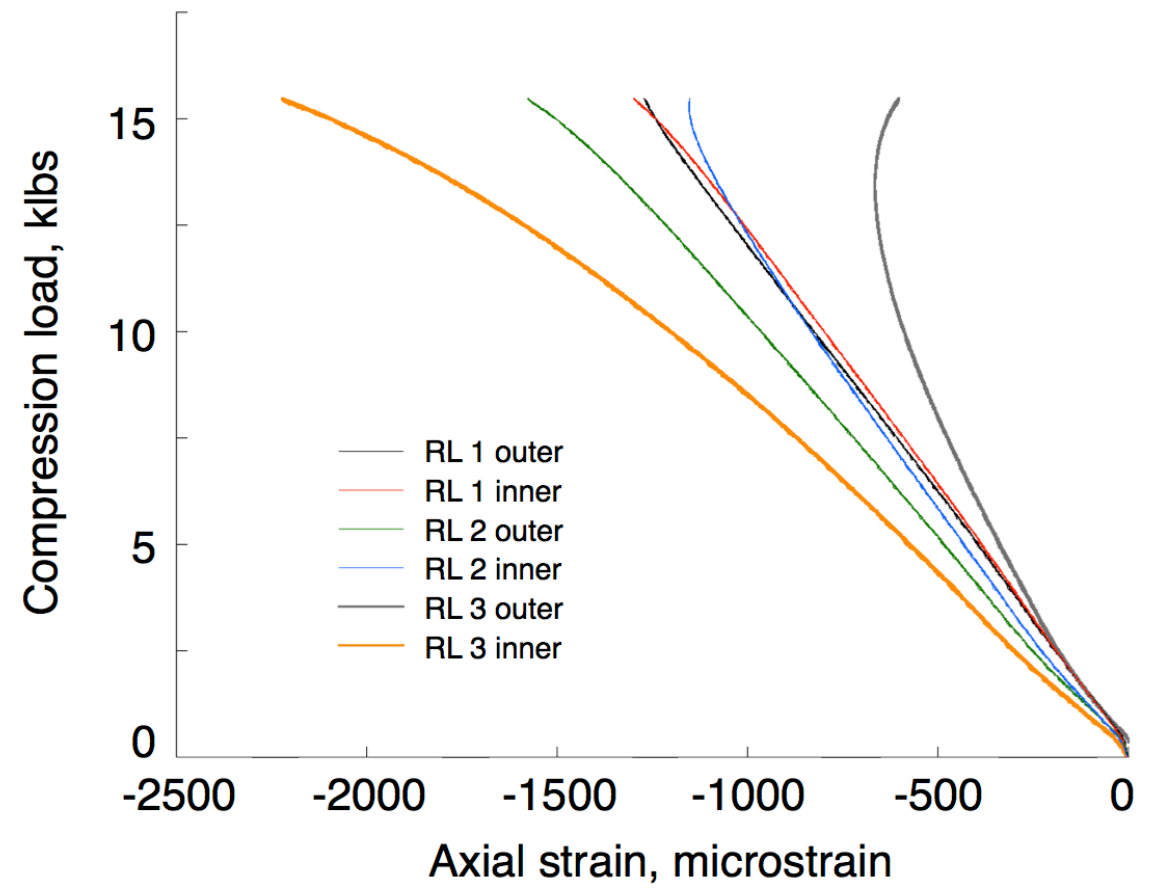

Figure 10. Shell B crown axial load vs. axial strain.

Outside-to-inside differences in strain for each gage pair are a quantitative measure of the local bending at that gage location, with much higher bending noted towards the potted ends than at the shell mid-length. This response is characteristic of the bending boundary layer that is generated near the ends of compression-loaded shells. The strains at RL 1 on Shell B are almost identical and parallel, and then cross over just before global buckling. This behavior indicates 
that the orientation of the transverse bending moment there changes from one direction (e.g., positive), to zero, to the opposite direction (e.g., negative) with increasing load.

Representative axial strain responses from gages on the back sides of the shells diametrically opposite from the cutouts are plotted in Figures 11 and 12 for Shells A and B, respectively. These positions are designated as RL 4, 5 and 6 in Figure 8, and are at the same axial stations as the ones selected above for the crown strains. The plotted strain responses for Shell A are also similar to those described above along the crown, but with slightly more initial nonlinearity. The strain traces at RL 4 and 5 on this shell are very close, indicating that minimal bending is occurring there. The traces at RL 4 actually cross over each other several times before global buckling takes place. The strains for Shell B are much more nonlinear, and show more bending near the shell ends than closer towards the shell mid-length, which suggests the presence of a bending boundary layer that is localized near the potted constraints on each shell end.

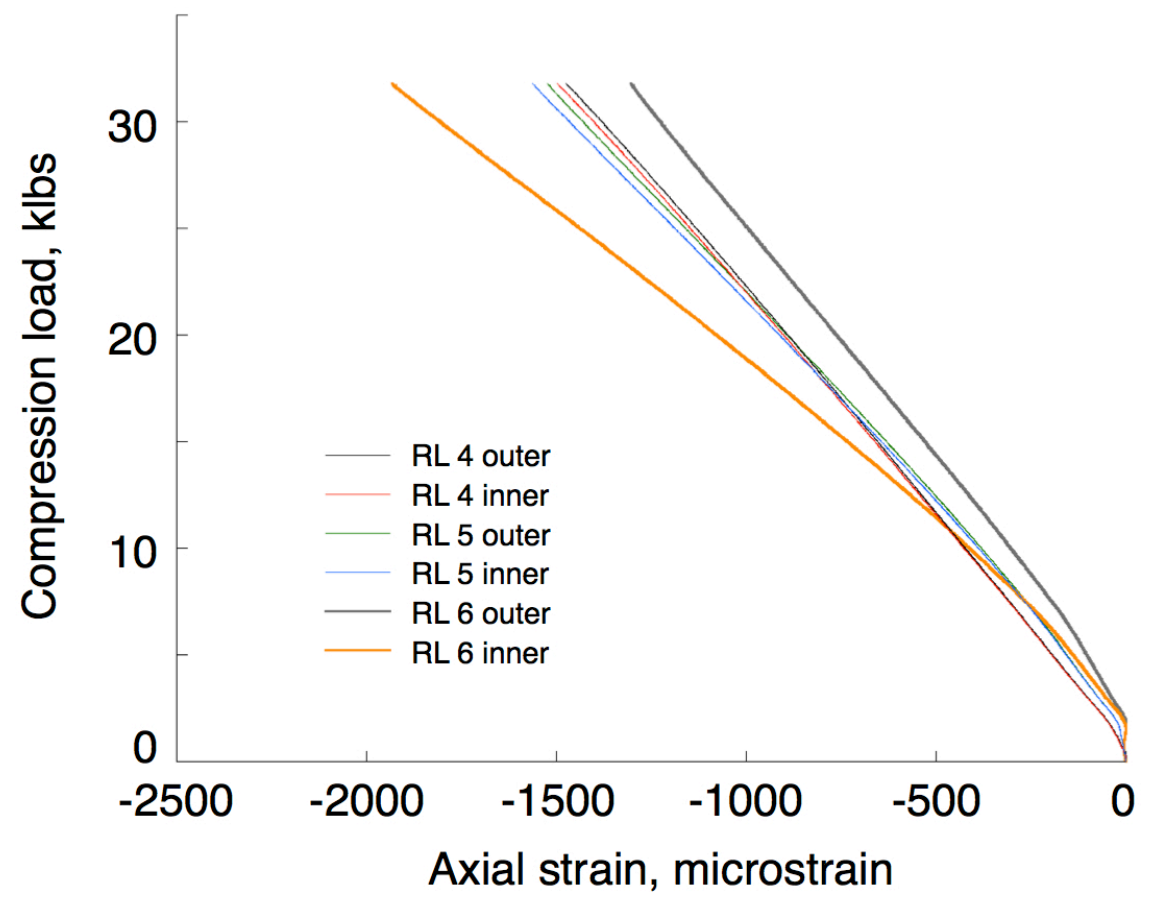

Figure 11. Shell A back side axial load vs. axial strain.

\section{Prebuckling strains around cutouts}

In this section, selected measurements from the 40 strain gages installed around the cutout are plotted against axial load from the shell compression tests. When facing the cutout as shown in Figures 4 and 8, 16 back-to-back strain gage rosettes are located at the 12, 1:30, 3, 4:30, 6, 7:30, 9 and 10:30 o'clock positions around the cutout perimeter. The 8 gage rosettes at the 12, 3, 6 and 9 o'clock positions (designated as RL 7, 8, 9 and 10 in Figure 8) are biaxial, with 2 gages in each rosette, and the remaining 8 rosettes are triaxial. In general, the strains at these locations are symmetric diametrically across the cutouts for both shells, and are also nonlinear with increasing load, the latter indicating that bending is occurring around the cutout perimeter. 


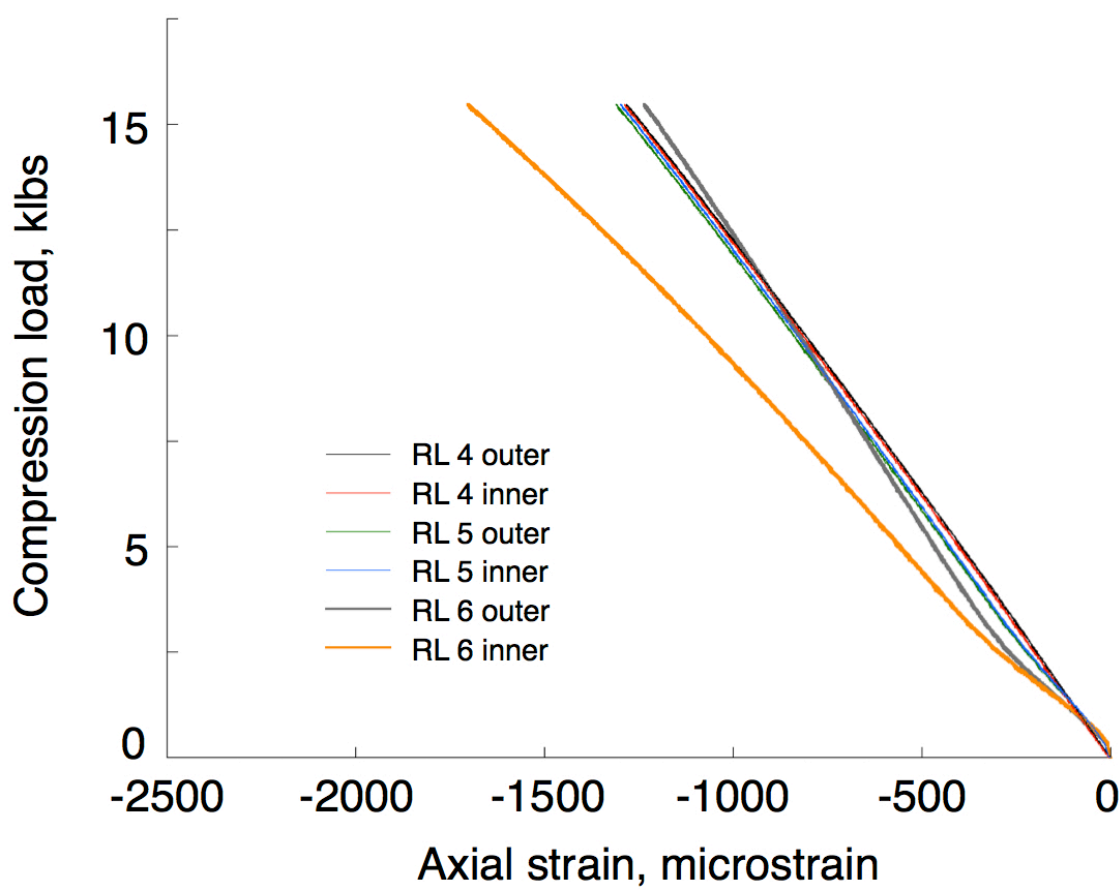

Figure 12. Shell B back side axial load vs. axial strain.

Axial strains at longitudinal (RL 7 and 9) and transverse (RL 8 and 10) locations around the cutout are plotted against the axial load for Shell A in Figure 13, and Shell B in Figure 14. Because of the high degree of symmetry noted in the strain data, each trace shown in these figures is plotted herein as the average of either the outer or inner surface strains along the specified axes. The averaged axial strains at the locations along the shell longitudinal axis are nearly equal and opposite, indicating the presence of local bending with minimal membrane strain (defined here as the average of the outer or inner surface strains). These data for Shell A begin to converge near global buckling, indicating an incipient bending moment reversal.

The averaged axial strains plotted at the transverse locations on either side of the cutout diverge relatively slowly at lower loads, and then much more rapidly after about $15 \mathrm{klbs}$ axial load for Shell A, and $7.5 \mathrm{klbs}$ for Shell B. This bimodal behavior is mildly suggestive of local buckling occurring at the cutout edge, however no associated loud noises or abrupt changes in the radial displacements were observed there during the tests. Qualitatively, the axial membrane strain at these locations is compressive, which corresponds with the overall compressive axial strain state applied to these shells.

The circumferential strain data at these same locations are then plotted in Figures 15 and 16 for Shells A and B, respectively. As for Figures 13 and 14, the outer and inner surface circumferential strains across the cutout are averaged separately before being plotted. The averaged circumferential strains shown in these figures show similar trends to the results described above for the axial data. However, the bending occurs in the opposite senses, so that Figures 13 and 15, and Figures 14 and 16, are (qualitative) mirror images of each other. In addition, the circumferential strains at RL 8 and 10 on the cutout vertical edges are about onehalf of the magnitudes of the axial strains at those locations. The membrane strains are also tensile there, indicating that the shell is growing radially under the compressive loading. 


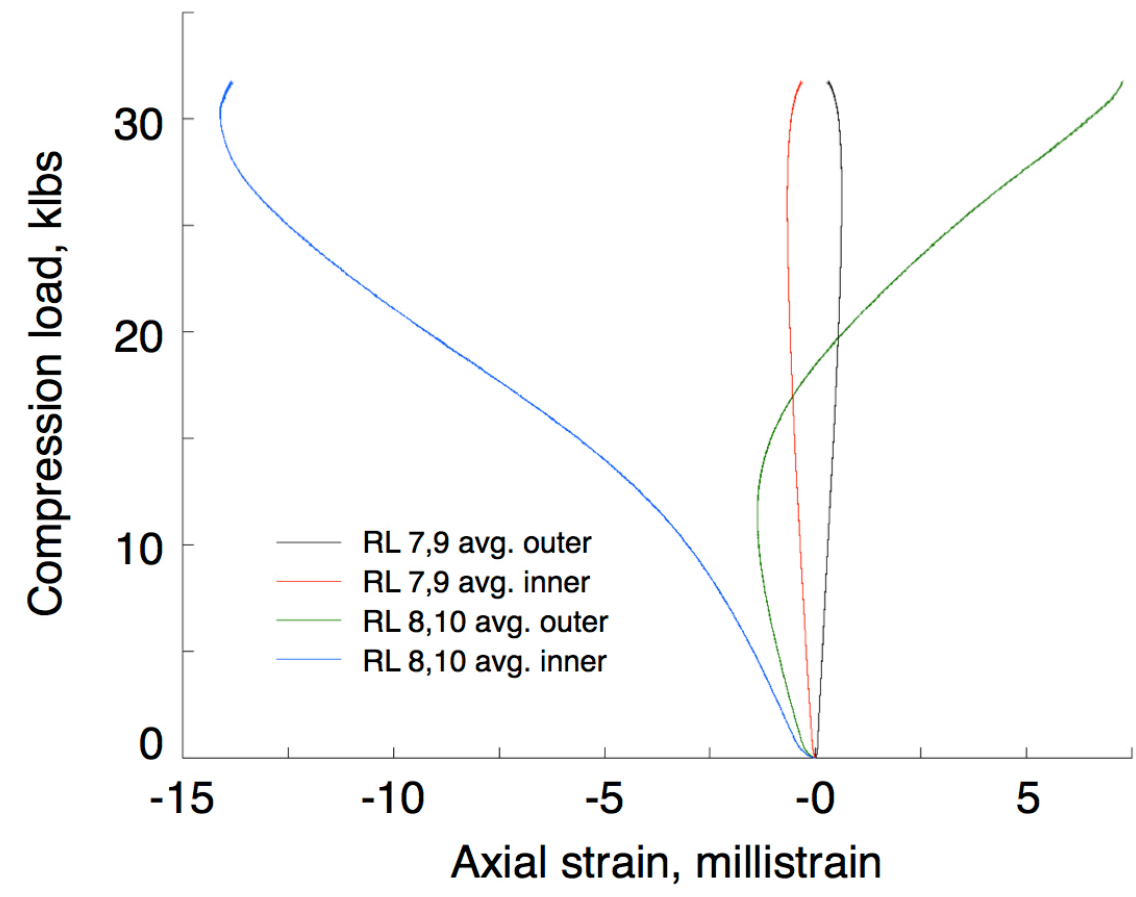

Figure 13. Shell A cutout axial load vs. axial strain.

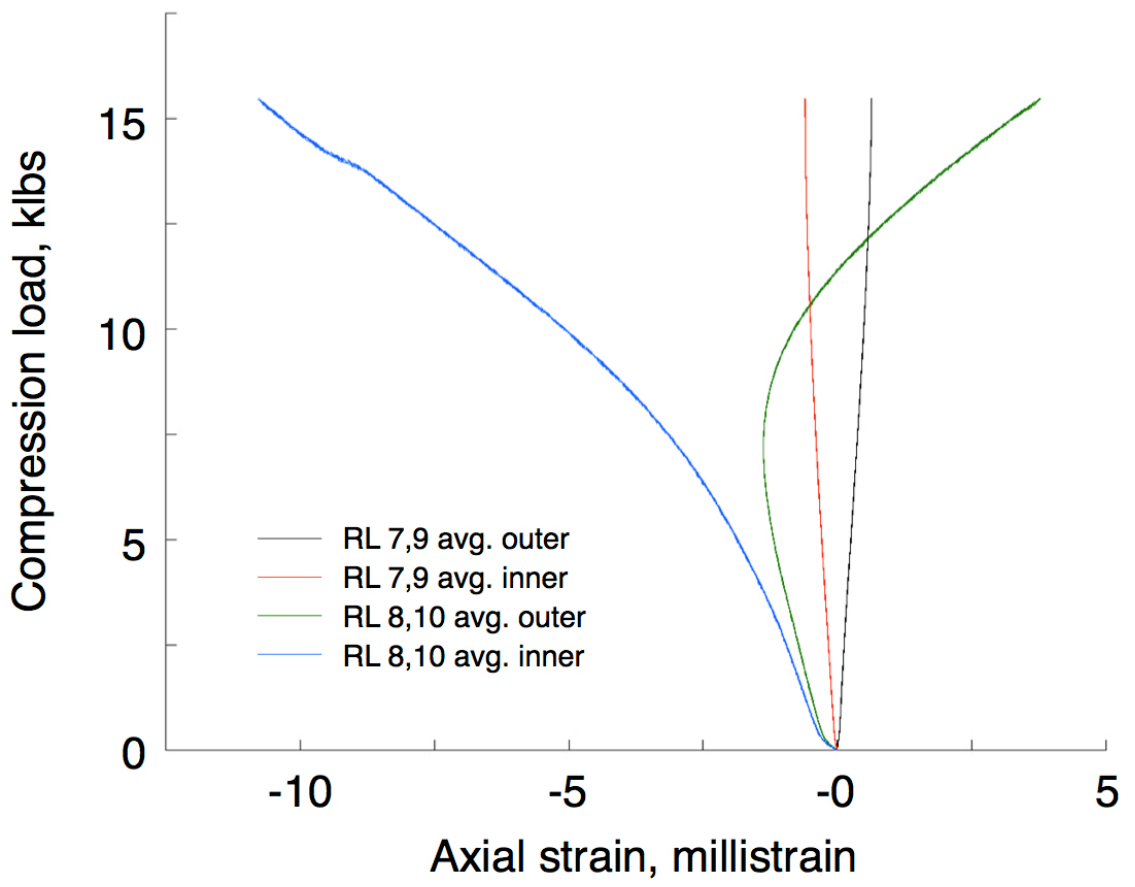

Figure 14. Shell B cutout axial load vs. axial strain.

\section{Full-field displacement measurements}

Measured radial displacement patterns from 3-dimensional digital image correlation systems are presented and discussed in this section. These systems are positioned to view both the crown of the shell, and side containing the cutout, during the shell compression tests. Qualitative contour 
plots of the radial displacements along the shell crowns are shown in Figures 17 and 18. The corresponding images taken of the shell sides with the cutouts are shown in Figures 19 and 20. The " 0 " notation on each side of the central scale corresponds to the color representing zero radial displacement in the adjacent contour plot.

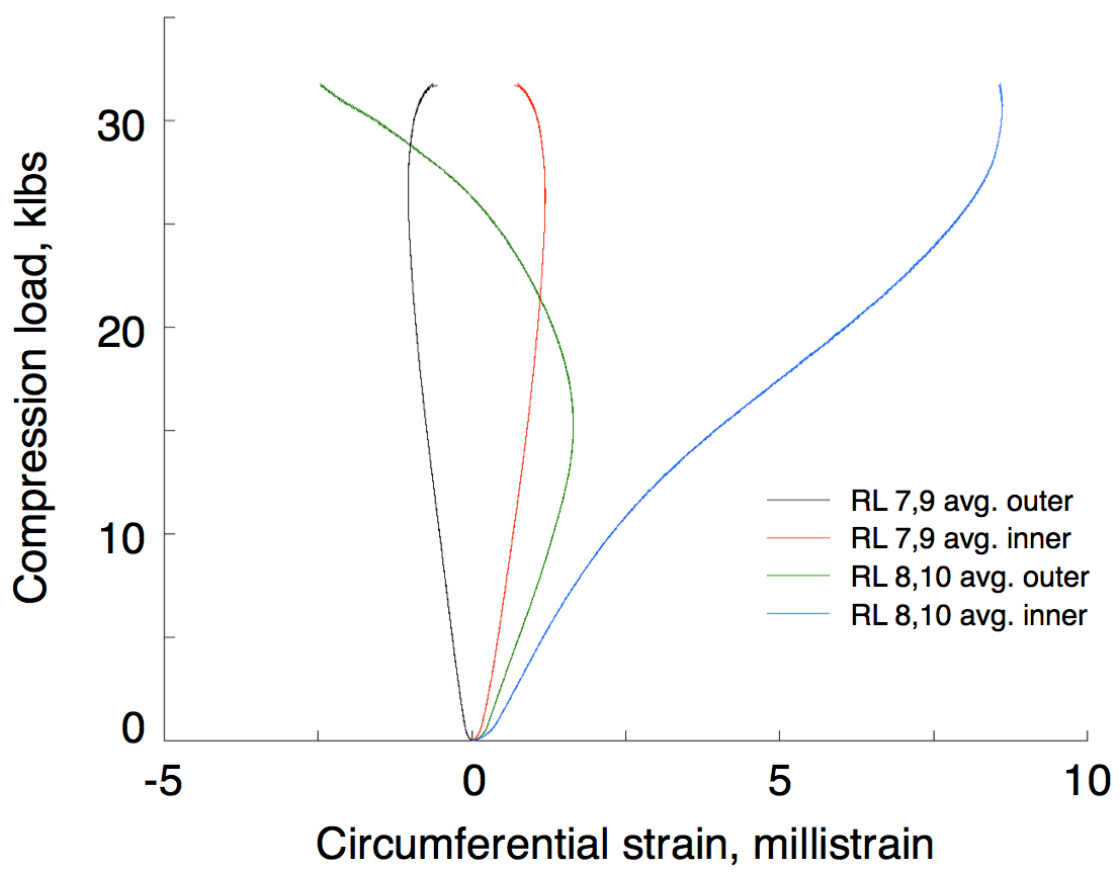

Figure 15. Shell A cutout axial load vs. circumferential strain.

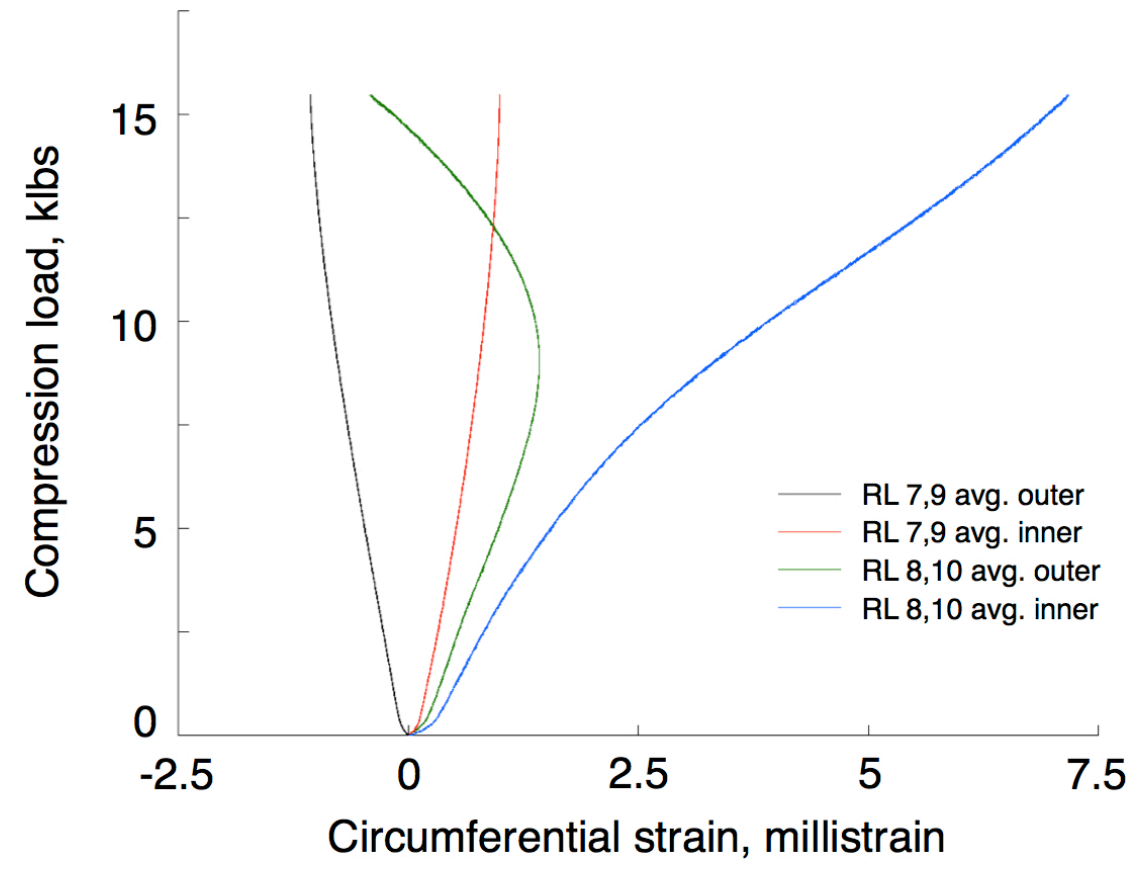

Figure 16. Shell B cutout axial load vs. circumferential strain. 


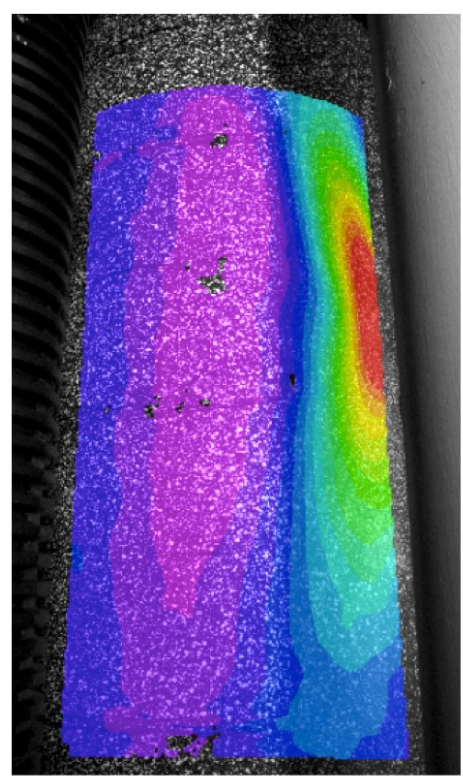

a. Buckling load $=31.8 \mathrm{klbs}$

Figure 17. Shell A crown measured radial displacements.

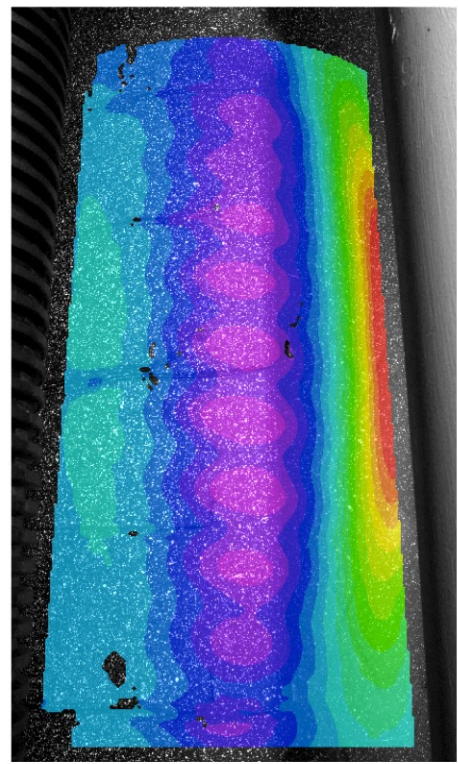

a. Buckling load $=15.5 \mathrm{klbs}$

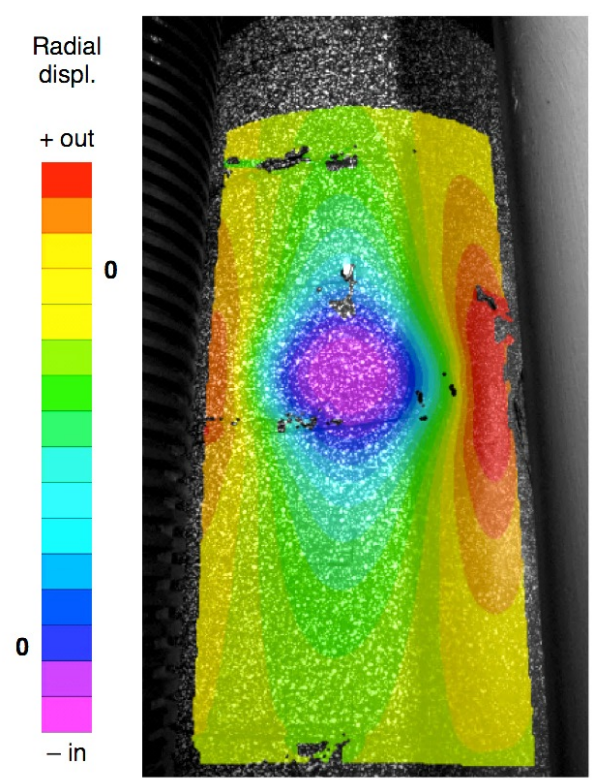

b. Postbuckling load $=20.3 \mathrm{klbs}$

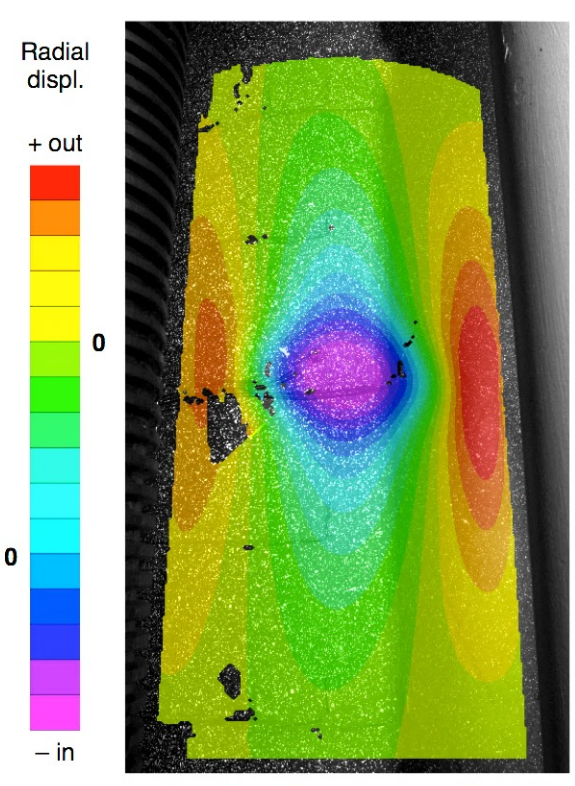

b. Postbuckling load $=10.5 \mathrm{klbs}$

Figure 18. Shell B crown measured radial displacements.

The image of Shell A taken just prior to global buckling in Figure 17a shows a shallow depressed region along the shell crown, with a pronounced ridge running parallel to the shell longitudinal axis located between the crown and the cutout to the right of the figure. The same image taken at stable postbuckling (Figure 17b) shows a deep central depression with two small ridges on either side. This postbuckled mode shape is consistent with the results observed in Ref. 10 for the same shell without the cutout. The corresponding images for Shell B are shown in Figures $18 \mathrm{a}$ and $18 \mathrm{~b}$, with pronounced axial waves clearly visible in the prebuckled image on the left. These results are also consistent with the results for the pristine shell without overlaps presented in Ref. 10. 


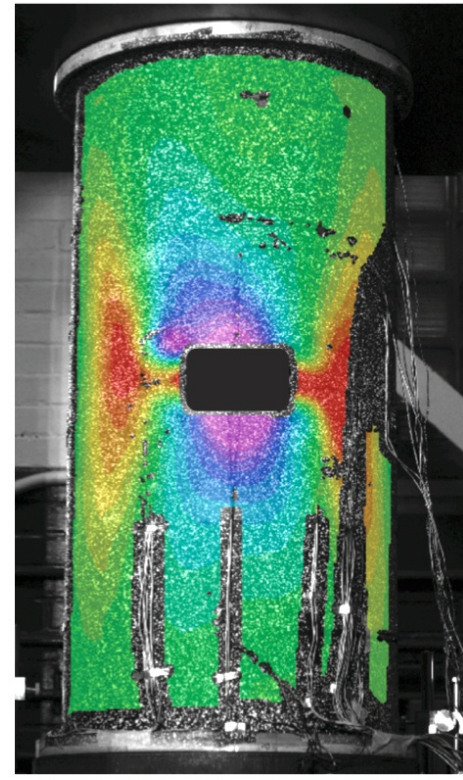

a. Buckling load $=31.8 \mathrm{klbs}$

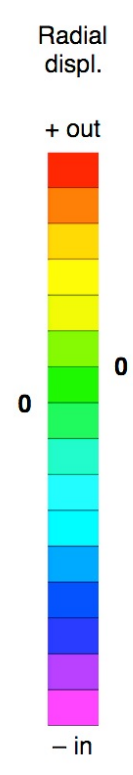

Figure 19. Shell A side measured radial displacements.

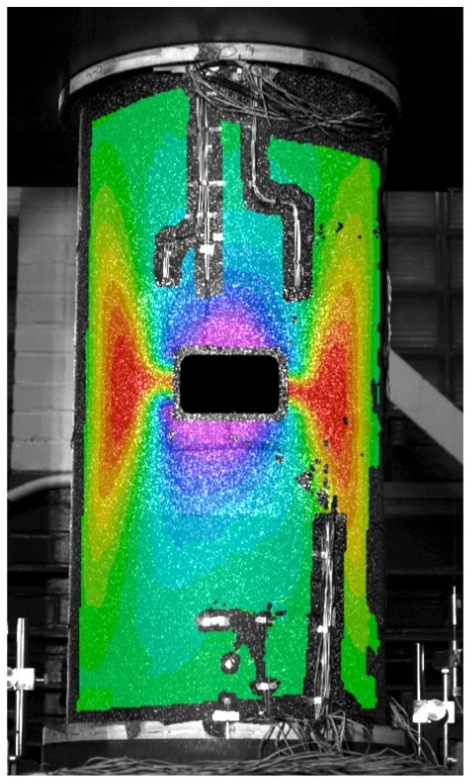

a. Buckling load $=15.5 \mathrm{klbs}$

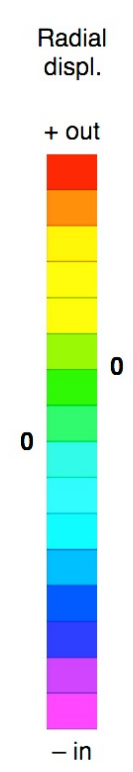

b. Postbuckling load $=10.5 \mathrm{klbs}$

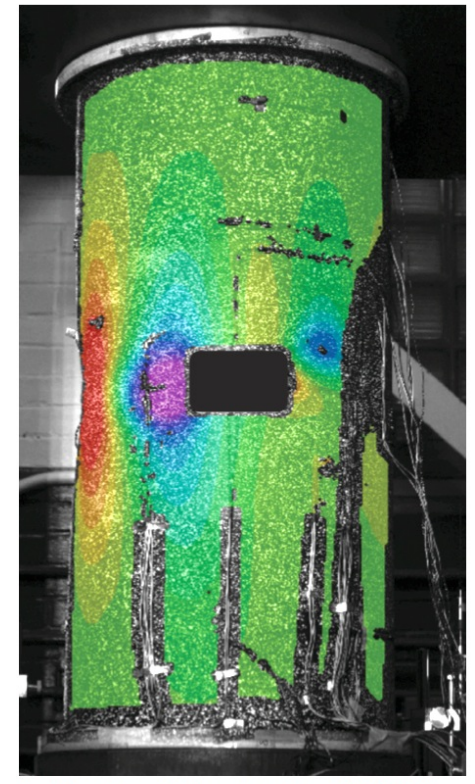

b. Postbuckling load $=20.3 \mathrm{klbs}$

Figure 20. Shell B side measured radial displacements.

Qualitative deformations for the side of Shell A containing the cutout, taken just before global buckling and at stable postbuckling, are shown in Figures 19a and 19b respectively, with corresponding results for Shell B in Figures 20a and 20b. In Figures 19a and 20a, the prebuckling radial displacements for the shells at the 12- and 6-o'clock positions around the cutout perimeter are directed inwards in a semi-circular shape, corresponding to the strain states at RL 7 and 9 in Figures 13 to 16. The corresponding prebuckling radial displacements at the 3and 9-o'clock positions (RL 8 and 10) are radially outwards starting at the cutout perimeter, and 
grow into radial bulges on either side of the cutout that are oriented parallel to the shell longitudinal axis.

After global buckling takes place, the displacement patterns on the shell sides then exhibit a single inward dimple located at or near the left side of the cutout. These results are shown qualitatively in Figures $19 \mathrm{~b}$ and $20 \mathrm{~b}$ for Shells A and B, respectively. The raised longitudinal ridges located to the left of the cutout in both of these figures, and to the right of the cutout in Figure 20b, correspond to the prominent ridges located on either side of the shell crowns that are noted previously in Figures 17b and 18b.

\section{Shell structural analyses}

The structural models of the baseline shells with and without tow overlaps developed previously and discussed in Ref. 10 are modified in this study to include the cutouts, as shown below in Figure 21. The assumed laminate thicknesses for the Shell A finite element model in Figure 21a range from 16 plies (red) on the shell crown and keel, to 8 plies (blue) on the sides. In comparison, the laminate thicknesses for the Shell B finite element model are assumed to be a constant 8 plies, and therefore are not plotted. The assumed fiber orientation angles for the first tow-steered ply (ply 3 ) in both models are shown in Figure 21b, and range from 45 degrees (red) on the shell sides, to 10 degrees (blue) on the shell crown and keel.

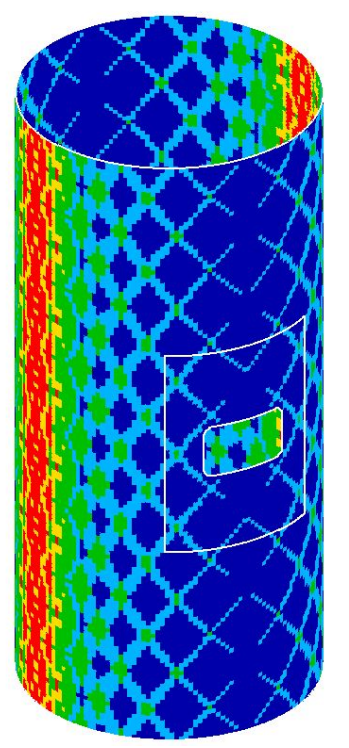

a. Shell A laminate thicknesses

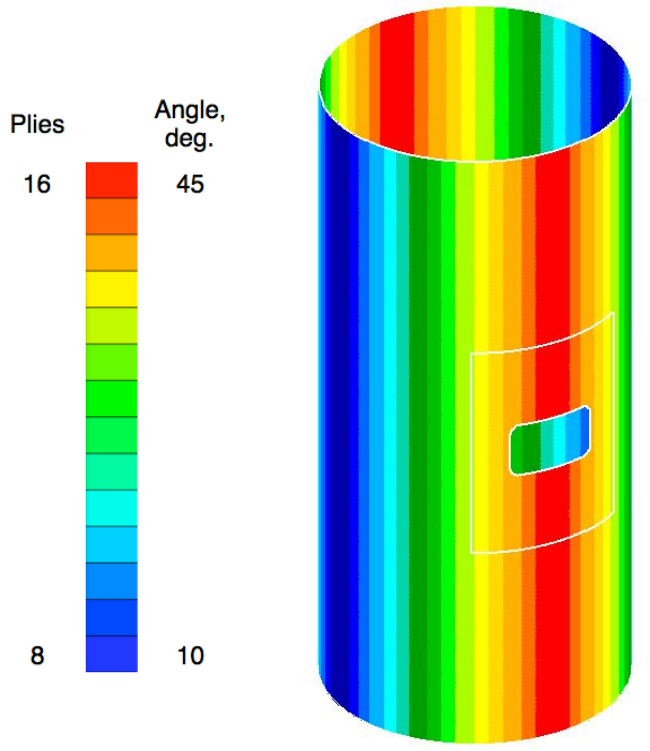

b. Ply 3 fiber orientation angles

Figure 21. Finite element model of tow-steered shell with cutout.

Because the baseline shell models are thoroughly described in Ref. 10, their details are not repeated here. However, the mesh density in the region surrounding the cutout, outlined in white in Figure 21, is increased, and a convergence study is first performed to determine the appropriate level of mesh refinement to best determine the structural response therein. In addition, the IM7/8552 measured ply principal stiffness $\mathrm{E}_{1}\left(18.04 \mathrm{Mlb} / \mathrm{in}^{2}\right)$ used in the analyses in Ref. 10 is increased by 8 percent to $19.48 \mathrm{Mlb} / \mathrm{in}^{2}$ for the present analyses. This slightly 
larger value of $E_{1}$ results from the increased fiber volume fraction in the lower average ply thickness of the cured shells (0.0050 in./ply, Ref. 9) when compared to the 0.0054-in. average cured ply thickness measured for the coupons cut from the witness panels used to determine the ply properties in Ref. 10 .

Preliminary linear structural analyses of the shells with cutouts are performed using the models described above. The results of these analyses, performed using the NASTRAN (Ref. 14) finite element code, are described in this section. Simulated end compression loads are applied to the models to predict the shells' axial stiffness and bifurcation buckling loads when the cutout is included. The results of these analyses are presented below in Table 2 .

Table 2. Predicted performance for shells with cutouts

$\begin{array}{lrr} & \text { Shell A } & \text { Shell B } \\ \text { Prebuckling axial stiffness, klb/in. } & 492.7 & 297.3 \\ \text { Local buckling load, klbs } & 19.3 & 10.4 \\ \text { Global buckling load, klbs } & 36.8 & 14.8\end{array}$

The predicted prebuckling axial stiffnesses of the shells compare very well with the measured data in Table 1, although both analytical values are slightly lower than the corresponding test results. For both shells, the lowest bifurcation buckling mode predicted from the shell structural analyses has a single axial half-wave, localized to the vertical edges of the cutout, that is directed radially outwards. This local buckling mode shape is shown in Figure 22, with the corresponding predicted buckling loads listed in Table 2. However, these predictions of discrete local buckling events do not match the actual shell response observed during the tests, in which the deformations around the cutout perimeter are highly nonlinear from the initiation of loading up to global buckling. In addition, the bifurcation buckling analyses predict the existence of several additional local buckling modes having combinations of one or two, symmetric or asymmetric, half-waves around the cutout perimeter. None of the DIC deformations observed during the shell tests confirm the existence of these other predicted local modes.

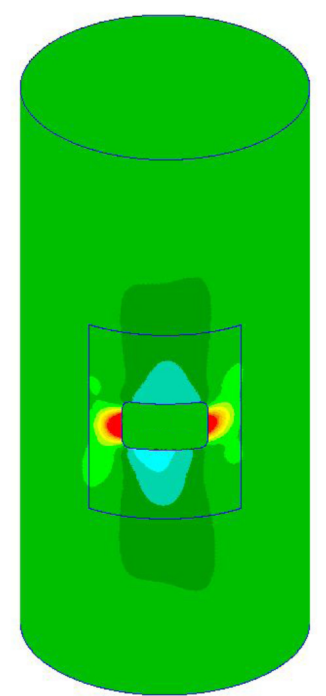

Figure 22. Predicted local buckling mode shape. 
The lowest global bifurcation buckling modes for the tow-steered composite shells are predicted to occur at 36.8 and $14.8 \mathrm{klbs}$ for Shells A and B, respectively, as shown in Table 2. These respective modes are numbered 7 and 5 for Shells A and B. The predicted global buckling load for Shell A is approximately 16 percent greater than the measured shell buckling load of 31.8 klbs listed in Table 1, while the predicted global buckling load for Shell B is less than 5 percent lower than its corresponding test value of $15.5 \mathrm{klbs}$. The corresponding analytical mode shapes are shown in Figure 23, and have a single circumferential half-wave and numerous axial waves located on the shell crown and keel simultaneously. The computed mode shape for Shell A has approximately 16 axial half-waves with much longer wavelengths than the approximately 23 half-waves predicted for Shell B. The DIC deformations observed for Shell B before buckling show better qualitative agreement with these predicted mode shapes than the corresponding results for Shell A.

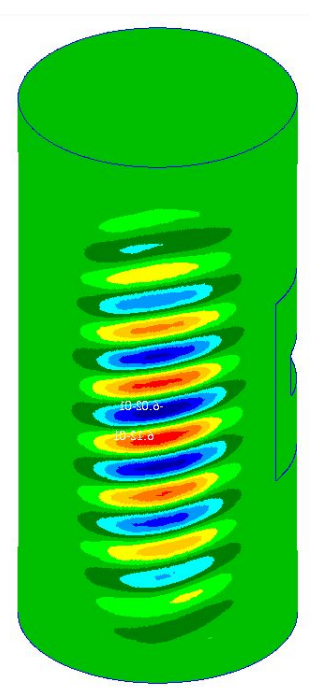

a. Shell A

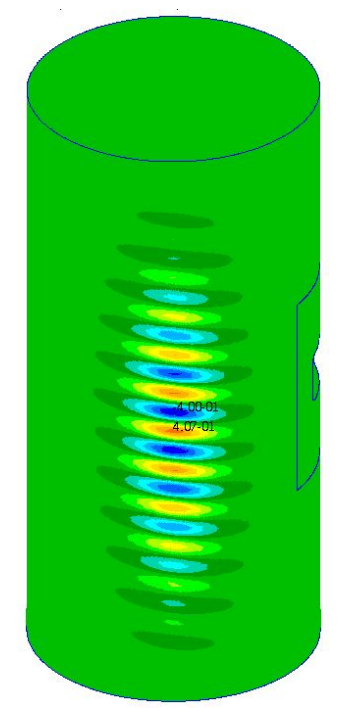

b. Shell B

Figure 23. Predicted global buckling mode shape.

\section{Concluding remarks}

Two advanced composite tow-steered shells, previously tested without cutouts, are evaluated with cutouts in this study. Both experimental and linear finite element analyses are used to characterize the shells' structural performance under end compression loads. The measured prebuckling axial stiffnesses and global buckling loads for the shells with cutouts are an average of 93 and 86 percent, respectively, of those of the pristine shells without cutouts.

The differences noted between the experimental buckling predictions and the linear finite element analyses indicate that more detailed geometrically nonlinear structural analyses must be performed to better replicate the actual structural response of these shells. One purpose of the present investigation is to gather useful information that can help to validate existing finite element analysis tools and methods, and to develop new ones.

It is also important to note that the tow-steered configuration of these shells was not originally designed with cutouts in mind. However, the results presented here show that both of the tow- 
steered composite shells with the cutouts can carry a significant portion of their baseline buckling loads without cutouts before also buckling elastically. The relatively small reductions in buckling loads observed during these tests clearly demonstrate the potential for using tow steering to mitigate some of the adverse effects of typical design features on the overall performance of aerospace structures. Even more aggressive use of tow steering and inclusion of the cutout geometry earlier in the structural design process may result in even further reductions in the impact of cutouts on structural performance.

Barring evidence of widespread damage resulting from the present tests, future plans are to enlarge the cutouts to be representative of a commercial aircraft cargo door and perform additional compression tests on each shell. When used in conjunction with previous studies, these results may help to better inform the future design, analysis and optimization of towsteered composite structures where the effects of cutouts are accounted for and mitigated throughout the entire design process.

This paper is respectfully dedicated to the memory of Dr. Michael F. Card, who served NASA Langley Research Center as a technical leader for 37 years until his retirement in 1995. Dr. Card, a true gentleman and mentor, was the Chief of the Structures and Dynamics Division when the first author began his career at NASA Langley.

\section{References}

1. Nemeth, M. P. and Starnes, J. H., Jr.: The NASA Monographs on Shell Stability Design Recommendations: A Review and Suggested Improvements. NASA/TP-1998-206290. January 1998.

2. Hilburger, M. W. and Starnes, J. H., Jr.: Buckling Behavior of Compression-Loaded Composite Cylindrical Shells with Reinforced Cutouts. International Journal of Nonlinear Mechanics, Vol. 43 (2005), pages 1005-1021.

3. Jegley, D. C., Tatting, B. F. and Gürdal, Z.: Optimization of Elastically Tailored Tow-Placed Plates with Holes. Proceedings of the 44th AIAA/ASME/ASCE/AHS/ASC Structures, Structural Dynamics and Materials Conference, Norfolk, Virginia, April 7-10, 2003. Paper no. AIAA 2003-1420.

4. Jegley, D. C., Tatting, B. F. and Gürdal, Z.: Tow-Steered Panels with Holes Subjected to Compression or Shear Loading. Proceedings of the 46th AIAA/ASME/ASCE/AHS/ASC Structures, Structural Dynamics and Materials Conference, Austin, Texas, April 18-21, 2005. Paper no. AIAA 2005-2081.

5. K. C. Wu: Advanced Tow-Steered Composites Technology Development. Proceedings of the NASA Fundamental Aeronautics Program 2012 Technical Conference. Cleveland, Ohio, March 12-15, 2012.

6. D. O. Evans: Fiber Placement. Handbook of Composites, 2nd edition, S. T. Peters, editor. Chapman \& Hall, London, 1998. Pages 476-487.

7. Lukaszewicz, D. H.-J.A., Ward, C., Potter, K. D.: The Engineering Aspects of Automated Prepreg Layup: History, Present and Future. Composites Part B: Engineering, Vol. 43, Issue 3 (April 2012), pages 997-1009. 
8. K. C. Wu: Design and Analysis of Tow-Steered Composite Shells Using Fiber Placement. Proceedings of the ASC 23rd Annual Technical Conference. Memphis, Tennessee, September 9-11, 2008. Paper no. 125.

9. K. C. Wu, B. F. Tatting, B. H. Smith, R. S. Stevens, G. P. Occhipinti, J. B. Swift, D. C. Achary and R. P. Thornburgh: Design and Manufacturing of Tow-Steered Composite Shells Using Fiber Placement. Proceedings of the 50th AIAA/ASME/ASCE/AHS/ASC Structures, Structural Dynamics and Materials Conference. Palm Springs, California, May 4-7, 2009. Paper no. AIAA 2009-2700.

10. K. C. Wu, B. K. Stanford, G. A. Hrinda, Z. Wang, R. A. Martin and H. A. Kim: Structural Assessment of Advanced Composite Tow-Steered Shells. Proceedings of the 54th AIAA/ASME/ASCE/AHS/ASC Structures, Structural Dynamics and Materials Conference. Boston, Massachusetts, April 8-11, 2013. Paper no. AIAA 2013-1769.

11. J. N. Zalameda, N. Rajic and M. Genest: Signal to Noise Studies on Thermographic Data with Fabricated Defects for Defense Structures. Proceedings of SPIE, Thermosense XXVIII, Jonathan J. Miles, G. Raymond Peacock and Kathryn M. Knettel, editors. Vol. 6205, April 17-20, 2006.

12. Anon.: 787-8 Airplane Characteristics for Airport Planning. D6-58333, rev. H, October 2012. The Boeing Company, Seattle, Washington. Downloaded 1 April 2013 from http://www.boeing.com/commercial/airports/acaps/787sec2.pdf.

13. M. A. Sutton, J. J. Orteu and H. Schreier: Image Correlation for Shape, Motion and Deformation Measurements: Basic Concepts, Theory and Applications. Springer, New York 2009.

14. Anon.: MSC Nastran 2012 Quick Reference Guide. MSC Software Corporation, Santa Ana, California, 2011. 